OPEN ACCESS

Edited by:

Wen Kong,

Wuhan Union Hospital, China

Reviewed by:

Lan Wu,

Vanderbilt University Medical Center,

United States

Taisen Iguchi,

National Institute for Basic Biology,

Japan

*Correspondence: Claudia Gabriela Pellizas claudia@fcq.unc.edu.ar

Specialty section: This article was submitted to

Experimental Endocrinology,

a section of the journal

Frontiers in Endocrinology

Received: 08 January 2019

Accepted: 15 May 2019

Published: 04 June 2019

Citation:

Montesinos MM and Pellizas CG (2019) Thyroid Hormone Action on

Innate Immunity.

Front. Endocrinol. 10:350

doi: 10.3389/fendo.2019.00350

\section{Thyroid Hormone Action on Innate Immunity}

\author{
María del Mar Montesinos and Claudia Gabriela Pellizas* \\ Facultad de Ciencias Químicas, Centro de Investigaciones en Bioquímica Clínica e Inmunología (CIBICI-CONICET) and \\ Departamento de Bioquímica Clínica, Universidad Nacional de Córdoba, Córdoba, Argentina
}

The interplay between thyroid hormone action and the immune system has been established in physiological and pathological settings. However, their connection is complex and still not completely understood. The thyroid hormones (THs), 3,3',5,5' tetraiodo-L-thyroxine (T4) and 3,3',5-triiodo-L-thyronine (T3) play essential roles in both the innate and adaptive immune responses. Despite much research having been carried out on this topic, the available data are sometimes difficult to interpret or even contradictory. Innate immune cells act as the first line of defense, mainly involving granulocytes and natural killer cells. In turn, antigen presenting cells, macrophages and dendritic cells capture, process and present antigens (self and foreign) to naïve $T$ lymphocytes in secondary lymphoid tissues for the development of adaptive immunity. Here, we review the cellular and molecular mechanisms involved in T4 and T3 effects on innate immune cells. An overview of the state-of-the-art of TH transport across the target cell membrane, TH metabolism inside these cells, and the genomic and non-genomic mechanisms involved in the action of THs in the different innate immune cell subsets is included. The present knowledge of TH effects as well as the thyroid status on innate immunity helps to understand the complex adaptive responses achieved with profound implications in immunopathology, which include inflammation, cancer and autoimmunity, at the crossroads of the immune and endocrine systems.

Keywords: thyroid hormones, innate immunity, neutrophils, natural killer cells, macrophages, dendritic cells

\section{INTRODUCTION}

Growing evidence compiled over recent decades has revealed a bidirectional crosstalk between thyroid hormones (THs) and the immune system. This interplay has been demonstrated for several pathophysiological conditions of the thyroid functioning and the innate and adaptive immunity. Many situations primarily affecting the action of THs have an impact on the characteristics and/or functions of immune cells, and are translated to host defense status and related disorders. In turn, immune-related disorders conduct to the most frequent thyroid dysfunctions, which have an autoimmune origin. The connection between these systems is complex and not well-understood. This article reviews the current evidence supporting the contribution of THs to the modulation of innate immunity at the cellular level. 


\section{Thyroid Hormone Action}

THs exert a pivotal role for normal development and function. The thyroid produces $3,3^{\prime}, 5,5^{\prime}$ tetraiodo-L-thyroxine (T4) and 3,3',5-triiodo-L-thyronine (T3), mainly under thyrotropin (TSH) regulation. While this gland secretes $100 \%$ of circulating T4, it provides only a low percentage of serum levels of the most physiologically active $\mathrm{TH}$ : T3, which for the major part derives from peripheral 5 deiodination of T4 (1). At the target cell level, the action of THs is genomic (nuclear) and non-genomic. The former requires $\mathrm{T} 3$ and the specific nuclear receptors (TRs): TR $\alpha 1, \operatorname{TR} \beta 1, \operatorname{TR} \beta 2$, and $\operatorname{TR} \beta 3$ (2) and is controlled by a multiprotein complex comprising both corepressors and coactivators (3).

Translocation of TRs from their synthesis in the cytosol to the nucleus is a functionally active process (4). In this regard, non-genomic effects exerted intracellularly by TRs and truncated variants occur rapidly, can be observed in the cytoplasm, mitochondria and other organelles, and are independent of nuclear receptor activity and protein synthesis. Many effects conducted by cytoplasmic TRs involve PI3K-dependent Akt activation (5). Furthermore, non-genomic actions of THs are also initiated at the plasma membrane through different proteins. The best studied is the integrin $\alpha \nu \beta 3$, which binds mainly T4 and tetraiodothyroacetic acid (tetrac), a derivative of T4, inducing activation of AMPK, PI3K/Akt, and MAPK $(6,7)$. Overall, THs interact with a wide variety of signaling pathways that are not yet fully deciphered.

Circulating levels of THs are not representative of what each cell type detects. Instead, the action of THs requires an appropriate interplay among membrane $\mathrm{TH}$ transporters, $\mathrm{TH}$ deiodinases and TR expression, and thus there is a fine-tuned cellular $\mathrm{TH}$ responsiveness. The main $\mathrm{TH}$ transporters include monocarboxylate transporters (MCT) 8 and 10, organic anion transporter polypeptides (OATPs) and large neutral amino acid transporters (LATs), with MCT8, MCT10, and LATs having a higher affinity for T3 than T4 uptake. Additionally, the cellular concentrations of THs are regulated by the activity of the 1,2 , and 3 iodothyronine deiodinases: D1, 2, and 3. D2 is an "activating" enzyme, responsible for the peripheral production of $50-80 \%$ of the body pool of T3 from T4. In contrast, D3 restrains T3 action, converting $\mathrm{T} 4$ and $\mathrm{T} 3$ into inactive metabolites. TH transporters and deiodinases exhibit a particular expression profile that is cellular and metabolic state specific $(8,9)$. Newly discovered actions of T4 and T3 metabolites, such as 3,5-diiodothyronine (3,5-T2), and 3-iodothyronamine (T1AM) are emerging (10).

\section{Innate Immunity}

The immune system includes cells that protect the organism from foreign antigens, such as microbes, cancer cells, toxins, and damage signals. It is simplistically referred to as innate and adaptive immunity. The former offers immediate protection against intruders, with specific cells being able to fight a wide range of pathogens, with the latter being specific and antigendependent (11). Moreover, adaptive immunity is orchestrated and directed by its innate counterpart.

The main innate cells are polymorphonuclear leukocytes (PMNL, mainly neutrophils), innate lymphoid cells (ILCs) including natural killer (NK) cells and cytokine-producing helper-like ILCs, innate T-like cells comprising NKT and $\gamma \delta \mathrm{T}$ cells, monocytes, macrophages and dendritic cells (DCs). Their complete classification and plethora of functions have been extensively reviewed (12-15).

The belief that innate immunity is non-specific was challenged after the description of pattern-recognition receptors and molecules that recognize pathogen and damage-associated molecular patterns from intruders $(16,17)$. Furthermore, the concept of exclusive memory for adaptive responses was weakened after the description of "trained innate memory," involving a heightened response upon re-exposure to a certain stimulus $(16,18)$ under the control of the cellular metabolism (19). Moreover, innate immune tolerance has also been demonstrated (20).

This review article focuses on the state-of-the-art of the $\mathrm{TH}$ mechanism of action and its effects on innate immunity at cellular level, with the pathophysiological role of the reported findings also discussed. The main effects of T3 and/or T4 in Neutrophils, NK cells, Macrophages and DCs are depicted in Figure 1 and considered below.

\section{Neutrophils}

Neutrophils are the first line of defense against bacteria and fungi, and also help to combat parasites and viruses (21). They travel from the blood to the inflammatory site where they engage and kill microorganisms and clear infections through chemotaxis, phagocytosis, and cytokine synthesis, and the release of reactive oxygen species (ROS) and granular proteins such as myeloperoxidase (MPO) (22). Classical concepts of neutrophil biology are being increasingly challenged by recent findings $(23,24)$.

Administration of $\mathrm{T} 3$ to rats increased the respiratory burst activity of isolated PMNLs with enhanced NADPH oxidase and MPO activities $(25,26)$. Accordingly, increased mitochondrial oxygen consumption and ROS production were reported in PMNLs from both Graves' disease and toxic adenoma patients (27). Moreover, T3 administration to euthyroid subjects induced ROS generation by PMNLs (28). However, a decrease in oxidative metabolism was registered in human PMNLs during hypothyroidism, which was reversed upon L-T4 substitution therapy (29). The authors suggest that this effect was unlikely to result from direct actions of THs on PMNLs, considering that $\mathrm{T} 3$ showed no appreciable effect on superoxide anion $\left(\mathrm{O}_{2}^{-}\right)$ generation in in vitro experiments with PMNLs from healthy donors. In addition, hypothyroidism causes changes in the lipid composition of PMNLs' membranes that may be involved in their impaired function (30). To note, human neutrophils express TR (31).

T4 and the TH metabolite 3,5-T2 as well as T3 induced respiratory-burst activity and stimulated MPO activity in human PMNLs. These effects were mediated by a non-genomic mechanism initiated at the plasma membrane, dependent on $\mathrm{PKC}$ and $\mathrm{Ca}^{+}$levels. Moreover, $\mathrm{O}_{2}^{-}$production in resting PMNLs of hyperthyroid patients was elevated compared with either controls or hypothyroid subjects (32). Furthermore, PMNLs 


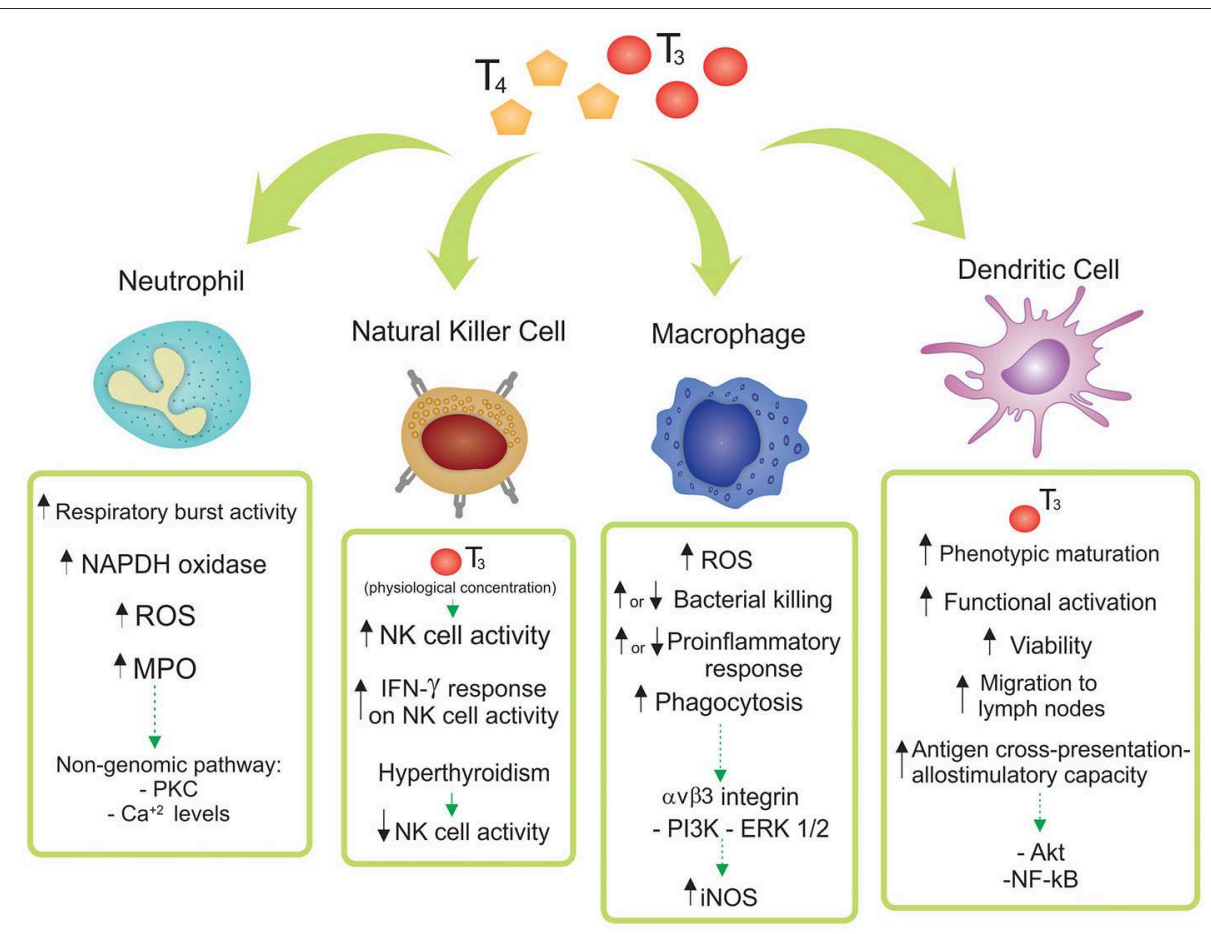

FIGURE 1 | Effects of thyroid hormones 3,3',5,5' tetraiodo-L-thyroxine (T4) and 3,3',5-triiodo-L-thyronine (T3) on innate immune cell subsets. The main reported effects of T3 and/or T4 in Neutrophils, Natural Killer (NK) cells, Macrophages and Dendritic Cells are depicted. Particular differences among the diverse origins of the cells (human, mice, cell lines, and/or tissue source) are shown and discussed in the main text.

express receptors for T1AM, a T4 derivative, involved in the chemosensory migration toward T1AM (33).

TH metabolism plays an important role in neutrophil function during infection. It has been demonstrated that D3 is strongly expressed in murine neutrophils during chronic chemical inflammation and in acute bacterial infection. Accordingly, human neutrophils express D3, D1, MCT10, and TR $\alpha 1$, which could therefore be involved in $\mathrm{TH}$ action in this cell type. Furthermore, evidence has supported the notion that D3 plays a role in the bacterial killing capacity of neutrophils, either through generation of iodide for the MPO system or through modulation of intracellular TH bioavailability (34). Recent results have demonstrated that intracellular TH levels are regulated by D3, playing a key role in neutrophil function in zebrafish, mice and humans (35).

\section{Natural Killer Cells}

NK cells mediate cytolytic activities against tumor and virusinfected targets. Of note, NK cells also possess traits of adaptive immunity and can acquire functional qualities associated with immunological memory (36). The studies of the effects of THs on these cells have produced conflicting results. A positive correlation between serum T3 concentration and NK cell activity in healthy elderly subjects was recorded but exogenous T3 administration increased NK cell activity only in old individuals who had T3 concentrations at the lower end of the reference range (37). Although NK cell functionality was impaired in
Graves' patients and restored in the euthyroid state $(38,39)$, in vitro treatment with $\mathrm{T} 4$ to peripheral blood lymphocytes from these patients did not show any increase in NK cell activity (40). In agreement, hyperthyroxinemia induced in mice reduced NK cell capacity to lyse target cells (41) whereas exogenous T4 or T3 administered to mice increased NK cell lytic activity (42), as well as during protein starvation (43), or aging (44).

Endogenous IFN- $\gamma$ plays a relevant role in the host defense against infectious and neoplastic diseases by mechanisms that involve modulation of the NK cell function $(45,46)$. Both T3 and T4 boosted IFN $\gamma$-response in murine NK cells $(44,47)$, while T4 amplified the effect induced by both IFN- $\gamma$ and IL-2 (48). These findings suggest a role for THs in the modulation of NK cell sensitivity to IFN- $\gamma$.

A recent study linked uterine NK cells (the most prominent leukocytes at the maternal-fetal interface) with THs. These cells express MCT8 and MCT10, as well as TR $\alpha 1$ and $\beta 1$ in the first trimester of human pregnancy. An increase of IL-6 secretion after T3 exposure in vitro was also reported (49).

\section{Monocytes-Macrophages}

Macrophages are strategically positioned in all tissues of the body and can recognize and remove pathogens, toxins, cellular debris, and apoptotic cells. Tissue-resident macrophages in adulthood rely on replenishment by bone marrow (BM)derived blood monocytes, with circulating monocytes being recruited to tissues by specific chemotactic factors. Among 
other names, tissue-resident macrophages are referred to as "microglia" in the central nervous system and "Kupffer cells" in the liver (50-52). Depending on the signal and the dose, a second stimulation can result in tolerance or trained immunity $(53,54)$. In response to stimuli, differentiated macrophages polarize to classically activated M1 or alternatively activated M2 macrophages, although a spectrum of phenotypes across the $\mathrm{M} 1 / \mathrm{M} 2$ continuum is recognized. M1 macrophages phagocytize and destroy microbes, eliminate tumor cells, and present antigens to $\mathrm{T}$ cells through ROS production, expression of inducible nitric oxide synthase (iNOS) and release of proinflammatory cytokines, thereby promoting $\mathrm{T}$ helper (Th) 1 responses (55). In contrast, M2 macrophages show an immunosuppressive phenotype characterized by a decreased antigen presentation to $\mathrm{T}$ cells and production of cytokines that stimulate Th2 responses. These regulatory cells are involved in tissue repair, promote tumor growth and exert antiparasitic effects (56).

In spite of controversial results concerning the expression of TR isoforms, macrophages express $\mathrm{TR} \alpha$ and $\beta$ (57-61). In addition, murine and human macrophage cell lines express D2, MCT10, and MCT8 (59). Over the past decade, it has become clear that shifts in cellular metabolism are determinants of macrophage function and phenotype (62). The activities of key enzymes of glycolysis are regulated by THs in these cells, affecting macrophage metabolism and function (63). Stimulation of the immune system in hyperthyroid rats revealed that monocyte migration and ROS production by macrophages were suppressed. In contrast, hypothyroidism enhanced ROS release, whereas monocyte migration was not affected (64).

THs enhanced the phagocytic activity of intraperitoneal macrophages from hypothyroid rats (64). Moreover, T4 administration to old mice also increased their phagocytic capacity (65). In agreement, a stimulatory effect of T4 (but not T3) on the phagocytosis process of cultured peritoneal mouse macrophages was reported (66). However, both THs enhanced bacteria-cell interaction and intracellular killing in mice RAW 264.7 and human THP-1 monocyte-derived macrophage cell lines (67). This mechanism involved the integrin $\alpha v \beta 3$, THinduced iNOS expression, generation of $\mathrm{NO}$ and triggering of the PI3K and ERK1/2 signaling pathways.

The inflammatory response exerted by macrophages was stimulated during hypothyroid condition and inhibited in the course of hyperthyroidism (68). T4 inhibited the migration inhibitory factor (MIF) in macrophages $(67,69)$, and in agreement, low plasma T4 concentrations augmented plasma MIF levels in both patients and rats with severe sepsis (69). Although T4 attenuated proinflammatory responses in vivo, no significant changes in IL- 6 and TNF $\alpha$ levels could be detected in T4-treated peritoneal macrophages from mice, or in mouse and human cell lines (67).

The "euthyroid sick syndrome" (or "nonthyroidal illness") is distinctive of critically ill patients with severe infections or sepsis, being characterized by low serum T3 and in serious cases by also low serum T4 without the expected increase in TSH (70). Interestingly, supplementation of T4 to rats and mice in bacterial infectious models enhanced animal survival and attenuated septicemia and inflammatory responses $(67,71)$. In agreement, hypothyroid mice exhibited increased mortality during inflammation induced by LPS, whereas circulating $\mathrm{T} 3$, through $\mathrm{TR} \beta 1$ signaling, protected animals from endotoxemia (57). However, it was reported that hyperthyroidism increased mice mortality in response to LPS. Noteworthy, Signal Transducer and Activator of Transcription 3 (STAT3) activation induced by LPS or IL-6 was inhibited by T3 through TR signaling in RAW 264.7 cells and in primary cultures of BM-derived macrophages. These authors suggested that inhibition of IL-6 signaling induced by $\mathrm{T} 3$ has potent regulatory functions during infection and inflammation (72).

Switching from M1 to the M2 phenotype protects the organism from excessive inflammation, whereas switching from M2 to M1 prevents allergic and asthmatic Th2 reactions, decreases the bactericidal properties of macrophages and favors the resolution of inflammation (63). In this regard, T3 reduced monocyte differentiation into macrophages and induced a M1 signature. In agreement, T3 decreased the expression of genes regulated by M2-activated macrophages through a TR $\beta 1$-mediated mechanism (58). Although comparable results were registered in RAW264.7 macrophages, a TR $\alpha$-dependence was revealed (73). In contrast, in a model of kidney obstruction, ligand-bound $\mathrm{TR} \alpha$ inhibited the NF- $\mathrm{B}$ pathway and proinflammatory cytokines in macrophages isolated at the inflammatory site (61).

The role of intracellular TH metabolism in macrophages has been extensively reported and reviewed by Boelen group (34), and is therefore not covered in this review. More recently, a reduction of intracellular T3 concentration due to a lack of D2 activity with impaired macrophage function was reported. Also, primary BM-derived macrophages treated with LPS decreased phagocytosis and proinflammatory cytokines in D2 $\mathrm{KO}$ mice (73), consistent with earlier results in RAW264.7 cells (59).

Modifications in the homeostatic conditions of the nervous tissue promote microglia activation, release of inflammatory mediators and phagocytosis of degenerating cells (74). Lima et al. (75) reported that rat microglial cells in culture express $\operatorname{TR} \alpha$ and $\operatorname{TR} \beta$, whereas other authors did not observe the latter (76). $\alpha \mathrm{V} \beta 3$ integrin has also been described in these cells (77), and in mice microglia, the TH transporters OATP4A1, LAT2, and MCT10 were also found $(78,79)$. It is known that T3 modulates microglial development (75) and functions such as migration and phagocytosis by genomic and non-genomic pathways (80). The molecular mechanism involves $\mathrm{T} 3$ uptake by TH transporters and binding to TRs, thus triggering multiple signaling pathways $(80,81)$. Moreover, T3 increased the release of soluble factors by the microglia through STAT3 activation, promoting glioma growth (82).

Liver is one of the most relevant TH target tissues. T3 induced acceleration of cellular $\mathrm{O}_{2}^{-}$consumption, resulting in elevated ROS and NO (83). In agreement, T3-stimulated free radical activity reduced the cellular antioxidant defenses leading to oxidative stress in rats, a phenomenon also observed in human hyperthyroidism $(84,85)$. Kupffer cells are main scavengers constantly clearing gut-derived pathogens from the blood, 
preventing liver diseases (86). T3 promoted hyperplasia and hypertrophy of these cells, with a resulting enhancement in the respiratory burst activity. Furthermore, T3-induced calorigenesis resulted in transient elevations in serum TNF- $\alpha$, determined by actions exerted in Kupffer cells and involving activation of NF-kB (87). The hepatic response induced by T3 involved cell proliferation associated with TNF- $\alpha$ generation by Kupffer cells (88).

\section{Dendritic Cells}

DCs are the main antigen presenting cells in the interface between innate and adaptive immunity. They integrate signals derived from infection or damage, and present processed antigen to naive $\mathrm{T}$ cells to tailor the appropriate $\mathrm{T}$ cell program. Recent advances in DC immunobiology have led to a clearer understanding of how $\mathrm{T}$ cell responses are shaped (89). The main DCs include conventional (classical or myeloid) DCs (cDCs, referred as DCs from now on) and plasmacytoid DCs (pDCs). The genetic signature of DCs from different tissues is similar, but differs from that of pDCs, monocytes and macrophages. To note, DCs are functionally different to macrophages $(89,90)$. Immature DCs (iDCs) have substantial endocytic activity but lower surface expression of major histocompatibility complex (MHC) class I and II proteins. After encountering any stimulus, DCs mature to undergo considerable cytoplasmic reorganization, transporting peptide-MHC complexes to the cell surface and upregulating costimulatory molecules (90). Recent studies highlighted the relevance of DC migration in the maintenance of immune surveillance. Immature DCs are rather immotile, and after processing foreign and self-antigens or damage signals undergo an activation process, leading to an increase in motility corresponding to upregulation of CC-chemokine receptor 7 (CCR7). The interaction of CCR7 with its ligand guides DCs toward secondary lymphoid organs (91).

The role of THs in the initiation of adaptive immunity remained uncertain for many years, with Mooij et al. providing the earliest clues that THs and other iodinated derivatives, mainly T3, favored the maturation of human peripheral blood monocytes into functional DCs (92). Many years later, our laboratory initiated a study on the effects of THs at the DC level (Figure 2). We observed the expression of TRs in BM-derived mouse DCs, principally the TR $\beta 1$ isoform, and mainly in the cytoplasm of both iDCs and LPS-matured DCs. The ability of physiological concentrations of $\mathrm{T} 3$ to induce phenotypic and functional activation of DCs and to drive a Th1 profile was also demonstrated (93). Mechanistically, this effect involved activation of the Akt and NF-kB pathways (94) and was counteracted by glucocorticoids (95). The requirement for an intact TR $\beta$-T3 signaling in T3-induced DC activation was confirmed by in vitro and in vivo studies $(94,96)$.

Interestingly, we showed that $\mathrm{T} 4$, the main circulating $\mathrm{TH}$, did not reproduce T3-dependent effects in DCs. The characterization of the mechanisms of TH transport and metabolism in DCs supports the notion of a homeostatic balance to prevent unspecific systemic activation of DCs. In this regard, DCs express MCT10 and LAT2 TH transporters, and mainly transport T3 with a favored involvement of MCT10, as its inhibition almost prevented T3 saturable uptake mechanism and reduced T3induced IL-12 production. In addition, DCs express D2 and D3, and exhibit both enzymatic activities with a prevalence toward TH inactivation (97).

Immunotherapy has become the fourth pillar of cancer care, complementing surgery, cytotoxic therapy, and radiotherapy (98). In this context, DCs have been the subject of numerous studies seeking new immunotherapeutic strategies against cancer. However, despite initial enthusiasm, disappointing results including a short half-life of DCs in circulation and induction of tolerogenic responses by death cells, have raised doubts regarding these approaches. Nevertheless, the increased understanding of DC immunobiology and the search for optimization strategies are allowing a more rational development of DC-based immunotherapies $(99,100)$. A new role for THs in this field has arisen, with T3 binding to $\operatorname{TR} \beta$ increasing mice DC viability and augmenting CCR7 expression, thereby driving migration of DCs to lymph nodes. Moreover, T3 stimulated the antigen cross-presentation ability of DCs, boosting antigen-specific cytotoxic T-cell responses. Also, vaccination with T3-stimulated DCs in mice bearing B16 melanoma inhibited tumor growth and prolonged host survival $(96,101)$. Overall, these results established the adjuvant effect of T3-TR $\beta$ signaling in DCs, identifying a DC vaccination approach in cancer immunotherapy.

Further recent in vitro and in vivo evidence has shed light on the molecular and cellular mechanisms driven by T3-conditioned murine DCs (102). Findings revealed an induction of a proinflammatory cytokine profile and a down-modulation of PDL expression in DCs. In co-cultures, these cells increased the frequency of IL-17-producing splenocytes, mainly by the $\gamma \delta$-T population. Thus, downregulation of tolerogenic $\mathrm{T}$ regulatory (Treg) cells and PD1 expression were induced, limiting the inhibitory signals and emphasizing the relevance of $\mathrm{T} 3$ as an additional immune-endocrine checkpoint.

The understanding of the effect of THs in human DCs is still limited. Dedecjus et al. (103) reported that the thyrometabolic state influenced the major human peripheral blood DCs, pDCs, and CDCs, with T4 substitution to thyroid cancer patients after surgery increasing the frequency of these cells and the expression of CD86 and HLA-DR (activation markers). In hypothyroid patients with Hashimoto's Thyroiditis, T4 supplementation exerted changes of peripheral blood DC subpopulations, with increased expression of costimulatory molecules (104). Although TRs in human DC populations have not yet been found, increased expression of CD86 by T3 addition to cell cultures of human peripheral blood pDCs was reported (103). Also, T3 increased the ability of human DCs to upregulate the proliferative response and secretion of IL-12 by peripheral blood mononuclear cells, similar to our findings in mice splenocytes co-cultured with T3-stimulated DCs (93).

The proinflammatory role of IL-12 and its involvement in Th1-mediated organ-specific autoimmune diseases (105) confer potential clinical relevance of the aforementioned studies. An increased synthesis of IL-12 by DCs obtained from hyperthyroid mice has been reported (106). Furthermore, patients with 


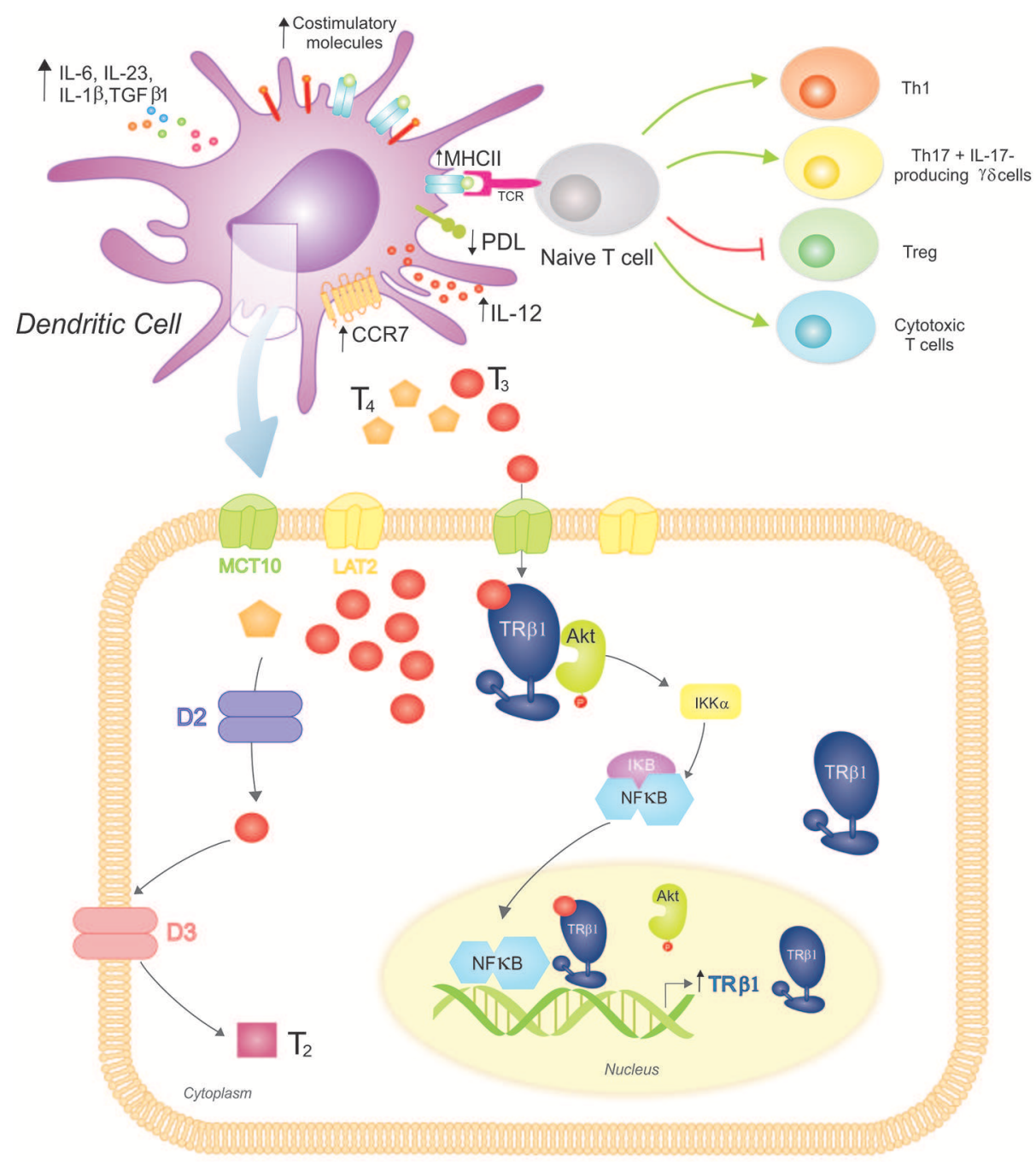

FIGURE 2 | 3,3',5-triiodo-L-thyronine (T3) promotes Dendritic Cell (DC) maturation and function, driving proinflammatory and cytotoxic adaptive responses. (Top) T3 promotes $\mathrm{DC}$ phenotypic maturation upregulating $\mathrm{MHCll}$ and costimulatory molecules. The functional $\mathrm{DC}$ activation promotes a proinflammatory cytokine phenotype (increased production of IL-12, IL-6, IL-23, IL-1 $\beta$, and TGF $\beta$ 1) that drives adaptive responses favoring the development of Th1 and Th17 T cells, IL-17-producing $\gamma \delta$ T cells, and cytotoxic T cells. In contrast, the Treg population is restrained. T3-conditioned DCs also augment CCR7 expression, which favors their migration to lymph nodes, where they present processed antigens in the context of MHCIl to specific T cell receptors (TCR) from naive T cells. T3 also modulates the immune checkpoint, reducing PDL expression on DCs and triggering the down-regulation of PD-1-expressing T cells (not shown). (Bottom) DCs take up T3 more effectively than T4 through MCT10 and LAT2. Inside DCs, D2 catalyzes the conversion of T4 to T3, whereas D3 inactivates T3 resulting in T2. These cells mainly express TR $\beta 1$ with a preferred cytoplasmic localization, where it co-localizes with Akt. Upon T3 binding to TR $\beta 1$, Akt is activated and translocated to the nucleus. This mechanism includes I $\mathrm{KB}$ degradation and thus NF- $\mathrm{KB}$ cytoplasmic-nuclear shuttling that acts as a transcription factor upregulating TR $\beta 1$ expression. An intact T3-TR 1 signaling is essential for T3-dependent DC induced effects.

Graves' disease exhibited elevated IL-12 circulating levels (107). Considering that DCs are involved in the pathogenesis of autoimmune thyroid diseases (108) and also their potential application for the treatment of these pathologies (109), further research should shed light in this field.

\section{CONCLUDING REMARKS}

The relationship between THs and innate immune cells is complex, with an improved knowledge still necessary.
Cellular and molecular signaling pathways involved in the crosstalk between THs and innate immune functions, and their role directing adaptive immunity have profound implications in immunopathology, including cancer and autoimmune manifestations of the thyroid gland, at the crossroads of the immune and endocrine systems. The etiopathogenic mechanism involved in both immune-related thyroid pathologies and immune disorders due to thyroid dysfunctions are now better understood. With a focus on particular cell subsets, further research will provide valuable 
tools for manipulating the immunogenic potential of innate immune cells to positively regulate the development of protective immunity, or negatively control the generation of autoimmune thyroid inflammation.

\section{AUTHOR CONTRIBUTIONS}

MM and CP: conception and design, analysis and interpretation of available data, writing, review, and revision of the manuscript. MM: design of figures. CP: general supervision.

\section{REFERENCES}

1. Williams GR, Bassett JH. Deiodinases: the balance of thyroid hormone: local control of thyroid hormone action: role of type 2 deiodinase. J Endocrinol. (2011) 209:261-72. doi: 10.1530/JOE-10-0448

2. Bernal J, Guadano-Ferraz A, Morte B. Thyroid hormone transportersfunctions and clinical implications. Nat Rev Endocrinol. (2015) 11:690. doi: 10.1038/nrendo.2015.113

3. Astapova I. Role of co-regulators in metabolic and transcriptional actions of thyroid hormone. J Mol Endocrinol. (2016) 56:7397. doi: 10.1530/JME-15-0246

4. Anyetei-Anum CS, Roggero VR, Allison LA. Thyroid hormone receptor localization in target tissues. $J$ Endocrinol. (2018) 237:R19-34. doi: 10.1530/JOE-17-0708

5. Cao X, Kambe F, Moeller LC, Refetoff S, Seo H. Thyroid hormone induces rapid activation of Akt/protein kinase B-mammalian target of rapamycinp70S6K cascade through phosphatidylinositol 3-kinase in human fibroblasts. Mol Endocrinol. (2005) 19:102-12. doi: 10.1210/me.2004-0093

6. Kalyanaraman H, Schwappacher R, Joshua J, Zhuang S, Scott BT, Klos $\mathrm{M}$, et al. Nongenomic thyroid hormone signaling occurs through a plasma membrane-localized receptor. Sci Signal. (2014) 7:ra48. doi: 10.1126/scisignal.2004911

7. Davis PJ, Goglia F, Leonard JL. Nongenomic actions of thyroid hormone. Nat Rev Endocrinol. (2016) 12:111-21. doi: 10.1038/nrendo.2015.205

8. Ortiga-Carvalho TM, Chiamolera MI, Pazos-Moura CC, Wondisford FE. Hypothalamus-pituitary-thyroid axis. Compr Physiol. (2016) 6:1387428. doi: 10.1002/cphy.c150027

9. Mendoza A, Hollenberg AN. New insights into thyroid hormone action. Pharmacol Ther. (2017) 173:135-45. doi: 10.1016/j.pharmthera.2017.02.012

10. Louzada RA, Carvalho DP. Similarities and differences in the peripheral actions of thyroid hormones and their metabolites. Front Endocrinol. (2018) 9:394. doi: 10.3389/fendo.2018.00394

11. Yatim KM, Lakkis FG. A brief journey through the immune system. Clin J Am Soc Nephrol. (2015) 10:1274-81. doi: 10.2215/CJN.10031014

12. Diefenbach A, Colonna M, Koyasu S. Development, differentiation, and diversity of innate lymphoid cells. Immunity. (2014) 41:35465. doi: 10.1016/j.immuni.2014.09.005

13. Woo SR, Corrales L, Gajewski TF. Innate immune recognition of cancer. Annu Rev Immunol. (2015) 33:44574. doi: 10.1146/annurev-immunol-032414-112043

14. Dadi S, Chhangawala S, Whitlock BM, Franklin RA, Luo CT, Oh SA, et al. Cancer immunosurveillance by tissue-resident innate lymphoid cells and innate-like T cells. Cell. (2016) 164:365-77. doi: 10.1016/j.cell.2016.01.002

15. Ebbo M, Crinier A, Vely F, Vivier E. Innate lymphoid cells: major players in inflammatory diseases. Nat Rev Immunol. (2017) 17:66578. doi: $10.1038 /$ nri.2017.86

16. Netea MG, Latz E, Mills KH, O'Neill LA. Innate immune memory: a paradigm shift in understanding host defense. Nat Immunol. (2015) 16:6759. doi: $10.1038 /$ ni.3178

17. Herwald H, Egesten A. On PAMPs and DAMPs. J Innate Immun. (2016) 8:427-8. doi: 10.1159/000448437

\section{FUNDING}

This study was supported by grants from Agencia Nacional de Promoción Científica y Tecnológica (ANPCyT, PICT-20160254 y PICT-2016-0037), Secretaría de Ciencia y Tecnología de la Universidad Nacional de Córdoba (SeCyT, 2018-2020), and Fundación Sales.

\section{ACKNOWLEDGMENTS}

The authors are extremely grateful to Isabel Maria Montesinos for her excellent assistance in the design and drawing of the figures.

18. Netea MG, Quintin J, van der Meer JW. Trained immunity: a memory for innate host defense. Cell Host Microbe. (2011) 9:355-61. doi: 10.1016/j.chom.2011.04.006

19. Penkov S, Mitroulis I, Hajishengallis G, Chavakis T. Immunometabolic crosstalk: an ancestral principle of trained immunity? Trends Immunol. (2019) 40:1-11. doi: 10.1016/j.it.2018.11.002

20. Dominguez-Andres J, Novakovic B, Li Y, Scicluna BP, Gresnigt MS, Arts RJW, et al. The itaconate pathway is a central regulatory node linking innate immune tolerance and trained immunity. Cell Metab. (2019) 29:211-20.e5. doi: 10.1016/j.cmet.2018.09.003

21. Ley K, Hoffman HM, Kubes P, Cassatella MA, Zychlinsky A, Hedrick CC, et al. Neutrophils: new insights and open questions. Sci Immunol. (2018) 3:eaat4579. doi: 10.1126/sciimmunol.aat4579

22. Mortaz E, Alipoor SD, Adcock IM, Mumby S, Koenderman L. Update on neutrophil function in severe inflammation. Front Immunol. (2018) 9:2171. doi: 10.3389/fimmu.2018.02171

23. Silvestre-Roig C, Hidalgo A, Soehnlein O. Neutrophil heterogeneity: implications for homeostasis and pathogenesis. Blood. (2016) 127:217381. doi: 10.1182/blood-2016-01-688887

24. Jablonska J, Granot Z. Neutrophil, quo vadis? J Leukoc Biol. (2017) 102:6858. doi: 10.1189/jlb.3MR0117-015R

25. Videla LA, Correa L, Rivera M, Sir T. Zymosan-induced luminolamplified chemiluminescence of whole blood phagocytes in experimental and human hyperthyroidism. Free Radic Biol Med. (1993) 14:66975. doi: 10.1016/0891-5849(93)90149-O

26. Fernandez V, Videla LA. On the mechanism of thyroid hormone-induced respiratory burst activity in rat polymorphonuclear leukocytes. Free Radic Biol Med. (1995) 19:359-63. doi: 10.1016/0891-5849(95)00016-Q

27. Szabo J, Foris G, Mezosi E, Nagy EV, Paragh G, Sztojka I, et al. Parameters of respiratory burst and arachidonic acid metabolism in polymorphonuclear granulocytes from patients with various thyroid diseases. Exp Clin Endocrinol Diabetes. (1996) 104:172-6. doi: 10.1055/s-00291211440

28. Magsino CH Jr., Hamouda W, Ghanim H, Browne R, Aljada A, Dandona P. Effect of triiodothyronine on reactive oxygen species generation by leukocytes, indices of oxidative damage, and antioxidant reserve. Metabolism. (2000) 49:799-803. doi: 10.1053/meta.2000.6263

29. Marino F, Guasti L, Cosentino M, De Piazza D, Simoni C, Piantanida E, et al. Thyroid hormone regulation of cell migration and oxidative metabolism in polymorphonuclear leukocytes: clinical evidence in thyroidectomized subjects on thyroxine replacement therapy. Life Sci. (2006) 78:10717. doi: $10.1016 /$ j.lfs.2005.06.016

30. Coria MJ, Carmona Viglianco YV, Marra CA, Gomez-Mejiba SE, Ramirez DC, Anzulovich AC, et al. Hypothyroidism modifies lipid composition of polymorphonuclear leukocytes. Cell Physiol Biochem. (2012) 29:71324. doi: 10.1159/000170987

31. Brisson-Lougarre A, Blum CJ. [Specific receptors for triiodothyronine in nuclei isolated from normal human polynuclear neutrophils]. C R Acad Sci III. (1985) 300:287-92.

32. Mezosi E, Szabo J, Nagy EV, Borbely A, Varga E, Paragh G, et al. Nongenomic effect of thyroid hormone on free-radical production in 
human polymorphonuclear leukocytes. J Endocrinol. (2005) 185:1219. doi: $10.1677 /$ joe. 1.05968

33. Babusyte A, Kotthoff M, Fiedler J, Krautwurst D. Biogenic amines activate blood leukocytes via trace amine-associated receptors TAAR1 and TAAR2. $J$ Leukoc Biol. (2013) 93:387-94. doi: 10.1189/jlb.0912433

34. van der Spek AH, Fliers E, Boelen A. Thyroid hormone metabolism in innate immune cells. J Endocrinol. (2017) 232:R67-81. doi: 10.1530/JOE-16-0462

35. van der Spek AH, Jim KK, Karaczyn A, van Beeren HC, Ackermans MT, Darras VM, et al. The thyroid hormone inactivating type 3 deiodinase is essential for optimal neutrophil function: observations from three species. Endocrinology. (2018) 159:826-35. doi: 10.1210/en.2017-00666

36. O'Sullivan TE, Sun JC, Lanier LL. Natural killer cell memory. Immunity. (2015) 43:634-45. doi: 10.1016/j.immuni.2015.09.013

37. Kmiec Z, Mysliwska J, Rachon D, Kotlarz G, Sworczak K, Mysliwski A. Natural killer activity and thyroid hormone levels in young and elderly persons. Gerontology. (2001) 47:282-8. doi: 10.1159/000052813

38. Papic M, Stein-Streilein J, Zakarija M, McKenzie JM, Guffee J, Fletcher MA. Suppression of peripheral blood natural killer cell activity by excess thyroid hormone. J Clin Invest. (1987) 79:404-8. doi: 10.1172/JCI112826

39. Wang PW, Luo SF, Huang BY, Lin JD, Huang MJ. Depressed natural killer activity in Graves' disease and during antithyroid medication. Clin Endocrinol. (1988) 28:205-14. doi: 10.1111/j.1365-2265.1988.tb03657.x

40. Lee MS, Hong WS, Hong SW, Lee JO, Kang TW. Defective response of natural killer activity to thyroxine in Graves' disease. Korean J Intern Med. (1990) 5:93-6. doi: 10.3904/kjim.1990.5.2.93

41. Stein-Streilein J, Zakarija M, Papic M, McKenzie JM. Hyperthyroxinemic mice have reduced natural killer cell activity. Evidence for a defective trigger mechanism. J Immunol. (1987) 139:2502-7.

42. Sharma SD, Tsai V, Proffitt MR. Enhancement of mouse natural killer cell activity by thyroxine. Cell Immunol. (1982) 73:83-97. doi: 10.1016/0008-8749(82)90437-3

43. Ingram KG, Crouch DA, Douez DL, Croy BA, Woodward B. Effects of triiodothyronine supplements on splenic natural killer cells in malnourished weanling mice. Int J Immunopharmacol. (1995) 17:2132. doi: 10.1016/0192-0561(94)00079-4

44. Provinciali M, Muzzioli M, Di Stefano G, Fabris N. Recovery of spleen cell natural killer activity by thyroid hormone treatment in old mice. Nat Immun Cell Growth Regul. (1991) 10:226-36.

45. Vivier E, Ugolini S. Natural killer cells: from basic research to treatments. Front Immunol. (2011) 2:18. doi: 10.3389/fimmu.2011.00018

46. Vivier E, Ugolini S, Blaise D, Chabannon C, Brossay L. Targeting natural killer cells and natural killer T cells in cancer. Nat Rev Immunol. (2012) 12:239-52. doi: 10.1038/nri3174

47. Provinciali M, Fabris N. Modulation of lymphoid cell sensitivity to interferon by thyroid hormones. J Endocrinol Invest. (1990) 13:18791. doi: $10.1007 / \mathrm{BF} 03349536$

48. Provinciali M, Muzzioli M, Fabris N. Thyroxine-dependent modulation of natural killer activity. J Exp Pathol. (1987) 3:617-22.

49. Vasilopoulou E, Loubiere LS, Lash GE, Ohizua O, McCabe CJ, Franklyn JA, et al. Triiodothyronine regulates angiogenic growth factor and cytokine secretion by isolated human decidual cells in a cell-type specific and gestational age-dependent manner. Hum Reprod. (2014) 29:116172. doi: 10.1093/humrep/deu046

50. Varol C, Mildner A, Jung S. Macrophages: development and tissue specialization. Annu Rev Immunol. (2015) 33:64375. doi: 10.1146/annurev-immunol-032414-112220

51. Ginhoux F, Guilliams M. Tissue-resident macrophage ontogeny and homeostasis. Immunity. (2016) 44:43949. doi: 10.1016/j.immuni.2016.02.024

52. Stocks CJ, Schembri MA, Sweet MJ, Kapetanovic R. For when bacterial infections persist: toll-like receptor-inducible direct antimicrobial pathways in macrophages. J Leukoc Biol. (2018) 103:35-51. doi: 10.1002/JLB.4RI0917-358R

53. Hoeksema MA, Glass CK. Nature and nurture of tissuespecific macrophage phenotypes. Atherosclerosis. (2019) 281:15967 doi: 10.1016/j.atherosclerosis.2018.10.005

54. Lo $\mathrm{CH}$, Lynch CC. Multifaceted roles for macrophages in prostate cancer skeletal metastasis. Front Endocrinol. (2018) 9:247. doi: 10.3389/fendo.2018.00247
55. Ruytinx P, Proost P, Van Damme J, Struyf S. Chemokine-induced macrophage polarization in inflammatory conditions. Front Immunol. (2018) 9:1930. doi: 10.3389/fimmu.2018.01930

56. Braga TT, Agudelo JS, Camara NO. Macrophages during the fibrotic process: $\mathrm{M} 2$ as friend and foe. Front Immunol. (2015) 6:602. doi: 10.3389/fimmu.2015.00602

57. Barish GD, Downes M, Alaynick WA, Yu RT, Ocampo CB, Bookout AL, et al. A Nuclear Receptor Atlas: macrophage activation. Mol Endocrinol. (2005) 19:2466-77. doi: 10.1210/me.2004-0529

58. Perrotta C, Buldorini M, Assi E, Cazzato D, De Palma C, Clementi E, et al. The thyroid hormone triiodothyronine controls macrophage maturation and functions: protective role during inflammation. Am J Pathol. (2014) 184:230-47. doi: 10.1016/j.ajpath.2013.10.006

59. Kwakkel J, Surovtseva OV, de Vries EM, Stap J, Fliers E, Boelen A. A novel role for the thyroid hormone-activating enzyme type 2 deiodinase in the inflammatory response of macrophages. Endocrinology. (2014) 155:272534. doi: 10.1210/en.2013-2066

60. Billon C, Canaple L, Fleury S, Deloire A, Beylot M, Dombrowicz D, et al. TRalpha protects against atherosclerosis in male mice: identification of a novel anti-inflammatory property for TRalpha in mice. Endocrinology. (2014) 155:2735-45. doi: 10.1210/en.2014-1098

61. Furuya F, Ishii T, Tamura S, Takahashi K, Kobayashi H, Ichijo M, et al. The ligand-bound thyroid hormone receptor in macrophages ameliorates kidney injury via inhibition of nuclear factor-kappaB activities. Sci Rep. (2017) 7:43960. doi: 10.1038/srep43960

62. Artyomov MN, Sergushichev A, Schilling JD. Integrating immunometabolism and macrophage diversity. Semin Immunol. (2016) 28:417-24. doi: 10.1016/j.smim.2016.10.004

63. Curi R, de Siqueira Mendes R, de Campos Crispin LA, Norata GD, Sampaio SC, Newsholme P. A past and present overview of macrophage metabolism and functional outcomes. Clin Sci. (2017) 131:1329-42. doi: 10.1042/CS20170220

64. Rosa LF, Safi DA, Curi R. Effect of hypo- and hyperthyroidism on the function and metabolism of macrophages in rats. Cell Biochem Funct. (1995) 13:141-7. doi: 10.1002/cbf.290130211

65. El-Shaikh KA, Gabry MS, Othman GA. Recovery of age-dependent immunological deterioration in old mice by thyroxine treatment. J Anim Physiol Anim Nutr. (2006) 90:244-54. doi: 10.1111/j.1439-0396.2005. 00602.x

66. Forner MA, Barriga C, Ortega E. Exercise-induced stimulation of murine macrophage phagocytosis may be mediated by thyroxine. J Appl Physiol. (1996) 80:899-903. doi: 10.1152/jappl.1996.80.3.899

67. Chen Y, Sjolinder M, Wang X, Altenbacher G, Hagner M, Berglund P, et al. Thyroid hormone enhances nitric oxide-mediated bacterial clearance and promotes survival after meningococcal infection. PLoS ONE. (2012) 7:e41445. doi: 10.1371/journal.pone.0041445

68. De Vito P, Incerpi S, Pedersen JZ, Luly P, Davis FB, Davis PJ. Thyroid hormones as modulators of immune activities at the cellular level. Thyroid. (2011) 21:879-90. doi: 10.1089/thy.2010.0429

69. Al-Abed Y, Metz CN, Cheng KF, Aljabari B, VanPatten S, Blau S, et al. Thyroxine is a potential endogenous antagonist of macrophage migration inhibitory factor. (MIF) activity. Proc Natl Acad Sci USA. (2011) 108:82247. doi: $10.1073 /$ pnas.1017624108

70. Ganesan K, Wadud K. Euthyroid Sick Syndrome. Treasure Island, FL: StatPearls (2018).

71. Little JS. Effect of thyroid hormone supplementation on survival after bacterial infection. Endocrinology. (1985) 117:14315. doi: 10.1210/endo-117-4-1431

72. Contreras-Jurado C, Alonso-Merino E, Saiz-Ladera C, Valino AJ, Regadera J, Alemany S, et al. The thyroid hormone receptors inhibit hepatic interleukin-6 signaling during endotoxemia. Sci Rep. (2016) 6:30990. doi: 10.1038/srep30990

73. van der Spek AH, Surovtseva OV, Jim KK, van Oudenaren A, Brouwer MC, Vandenbroucke-Grauls C, et al. Regulation of intracellular triiodothyronine is essential for optimal macrophage function. Endocrinology. (2018) 159:2241-52. doi: 10.1210/en.2018-00053

74. Lenz KM, Nelson LH. Microglia and beyond: innate immune cells as regulators of brain development and behavioral function. Front Immunol. (2018) 9:698. doi: 10.3389/fimmu.2018.00698 
75. Lima FR, Gervais A, Colin C, Izembart M, Neto VM, Mallat M. Regulation of microglial development: a novel role for thyroid hormone. J Neurosci. (2001) 21:2028-38. doi: 10.1523/JNEUROSCI.21-06-02028.2001

76. Lourbopoulos A, Mourouzis I, Karapanayiotides T, Nousiopoulou E, Chatzigeorgiou S, Mavridis T, et al. Changes in thyroid hormone receptors after permanent cerebral ischemia in male rats. J Mol Neurosci. (2014) 54:78-91. doi: 10.1007/s12031-014-0253-3

77. Jin YC, Lee H, Kim SW, Kim ID, Lee HK, Lee Y, et al. Intranasal delivery of RGD motif-containing osteopontin icosamer confers neuroprotection in the postischemic brain via alphavbeta3 integrin binding. Mol Neurobiol. (2016) 53:5652-63. doi: 10.1007/s12035-015-9480-Z

78. Wirth EK, Roth S, Blechschmidt C, Holter SM, Becker L, Racz I, et al. Neuronal 3',3,5-triiodothyronine. (T3) uptake and behavioral phenotype of mice deficient in Mct8, the neuronal T3 transporter mutated in Allan-Herndon-Dudley syndrome. J Neurosci. (2009) 29:943949. doi: 10.1523/JNEUROSCI.6055-08.2009

79. Braun D, Kinne A, Brauer AU, Sapin R, Klein MO, Kohrle J, et al. Developmental and cell type-specific expression of thyroid hormone transporters in the mouse brain and in primary brain cells. Glia. (2011) 59:463-71. doi: 10.1002/glia.21116

80. Mori Y, Tomonaga D, Kalashnikova A, Furuya F, Akimoto N, Ifuku M, et al. Effects of 3,3'5-triiodothyronine on microglial functions. Glia. (2015) 63:906-20. doi: 10.1002/glia.22792

81. Noda M. Thyroid hormone in the CNS: contribution of neuron-glia interaction. Vitam Horm. (2018) 106:313-31. doi: 10.1016/bs.vh.2017.05.005

82. Perrotta C, De Palma C, Clementi E, Cervia D. Hormones and immunity in cancer: are thyroid hormones endocrine players in the microglia/glioma cross-talk? Front Cell Neurosci. (2015) 9:236. doi: 10.3389/fncel.2015.00236

83. Kowalik MA, Columbano A, Perra A. Thyroid hormones, thyromimetics and their metabolites in the treatment of liver disease. Front Endocrinol. (2018) 9:382. doi: 10.3389/fendo.2018.00382

84. Videla LA. Energy metabolism, thyroid calorigenesis, and oxidative stress: functional and cytotoxic consequences. Redox Rep. (2000) 5:26575. doi: 10.1179/135100000101535807

85. Varela P, Tapia G, Fernandez V, Videla LA. The role of thyroid hormone calorigenesis in the redox regulation of gene expression. Biol Res. (2006) 39:611-7. doi: 10.4067/S0716-97602006000500004

86. Krenkel O, Tacke F. Liver macrophages in tissue homeostasis and disease. Nat Rev Immunol. (2017) 17:306-21. doi: 10.1038/nri.2017.11

87. Videla LA, Fernandez V, Tapia G, Varela P. Thyroid hormone calorigenesis and mitochondrial redox signaling: upregulation of gene expression. Front Biosci. (2007) 12:1220-8. doi: 10.2741/2140

88. Fernandez V, Reyes S, Bravo S, Sepulveda R, Romanque P, Santander G, et al. Involvement of Kupffer cell-dependent signaling in T3-induced hepatocyte proliferation in vivo. Biol Chem. (2007) 388:831-7. doi: 10.1515/BC.2007.101

89. Eisenbarth SC. Dendritic cell subsets in $\mathrm{T}$ cell programming: location dictates function. Nat Rev Immunol. (2019) 19:89103. doi: 10.1038/s41577-018-0088-1

90. Satpathy AT, Kc W, Albring JC, Edelson BT, Kretzer NM, Bhattacharya $\mathrm{D}$, et al. Zbtb46 expression distinguishes classical dendritic cells and their committed progenitors from other immune lineages. J Exp Med. (2012) 209:1135-52. doi: 10.1084/jem.20120030

91. Worbs T, Hammerschmidt SI, Forster R. Dendritic cell migration in health and disease. Nat Rev Immunol. (2017) 17:30-48. doi: 10.1038/nri.2016.116

92. Mooij P, Simons PJ, de Haan-Meulman M, de Wit HJ, Drexhage HA. Effect of thyroid hormones and other iodinated compounds on the transition of monocytes into veiled/dendritic cells: role of granulocyte-macrophage colony-stimulating factor, tumour-necrosis factor-alpha and interleukin-6. J Endocrinol. (1994) 140:503-12. doi: 10.1677/joe.0.1400503

93. Mascanfroni I, Montesinos Mdel M, Susperreguy S, Cervi L, Ilarregui JM, Ramseyer VD, et al. Control of dendritic cell maturation and function by triiodothyronine. FASEB J. (2008) 22:1032-42. doi: 10.1096/fj.07-8652com

94. Mascanfroni ID, Montesinos Mdel M, Alamino VA, Susperreguy S, Nicola JP, Ilarregui JM, et al. Nuclear factor. (NF)-kappaB-dependent thyroid hormone receptor betal expression controls dendritic cell function via Akt signaling. $J$ Biol Chem. (2010) 285:9569-82. doi: 10.1074/jbc.M109.071241

95. Montesinos MM, Alamino VA, Mascanfroni ID, Susperreguy S, Gigena N, Masini-Repiso AM, et al. Dexamethasone counteracts the immunostimulatory effects of triiodothyronine. (T3) on dendritic cells. Steroids. (2012) 77:67-76. doi: 10.1016/j.steroids.2011.10.006

96. Alamino VA, Mascanfroni ID, Montesinos MM, Gigena N, Donadio AC, Blidner AG, et al. Antitumor responses stimulated by dendritic cells are improved by triiodothyronine binding to the thyroid hormone receptor beta. Cancer Res. (2015) 75:1265-74. doi: 10.1158/0008-5472.CAN-14-1875

97. Gigena N, Alamino VA, Montesinos MD, Nazar M, Louzada RA, Wajner $\mathrm{SM}$, et al. Dissecting thyroid hormone transport and metabolism in dendritic cells. J Endocrinol. (2017) 232:337-50. doi: 10.1530/JOE-16-0423

98. Emens LA, Ascierto PA, Darcy PK, Demaria S, Eggermont AMM, Redmond WL, et al. Cancer immunotherapy: opportunities and challenges in the rapidly evolving clinical landscape. Eur J Cancer. (2017) 81:11629. doi: 10.1016/j.ejca.2017.01.035

99. Constantino J, Gomes C, Falcao A, Cruz MT, Neves BM. Antitumor dendritic cell-based vaccines: lessons from 20 years of clinical trials and future perspectives. Transl Res. (2016) 168:74-95. doi: 10.1016/j.trsl.2015. 07.008

100. Veglia F, Gabrilovich DI. Dendritic cells in cancer: the role revisited. Curr Opin Immunol. (2017) 45:43-51. doi: 10.1016/j.coi.2017.01.002

101. Alamino VA, Montesinos MM, Rabinovich GA, Pellizas CG. The thyroid hormone triiodothyronine reinvigorates dendritic cells and potentiates anti-tumor immunity. Oncoimmunology. (2016) 5:e1064579. doi: 10.1080/2162402X.2015.1064579

102. Alamino VA, Montesinos MDM, Soler MF, Giusiano L, Gigena N, Fozzatti L, et al. Dendritic cells exposed to triiodothyronine deliver pro-inflammatory signals and amplify IL-17-driven immune responses. Cell Physiol Biochem. (2019) 52:354-67. doi: 10.33594/000000025

103. Dedecjus M, Stasiolek M, Brzezinski J, Selmaj K, Lewinski A. Thyroid hormones influence human dendritic cells' phenotype, function, and subsets distribution. Thyroid. (2011) 21:533-40. doi: 10.1089/thy.2010.0183

104. Stasiolek M, Dedecjus M, Adamczewski Z, Sliwka PW, Brzezinski J, Lewinski A. Effect of L-thyroxine treatment on peripheral blood dendritic cell subpopulations in patients with Hashimoto's thyroiditis. Folia Histochem Cytobiol. (2014) 52:138-43. doi: 10.5603/FHC.2014.0013

105. Trinchieri G. Interleukin-12 and the regulation of innate resistance and adaptive immunity. Nat Rev Immunol. (2003) 3:133-46. doi: 10.1038/nri1001

106. Tamura M, Matsuura B, Miyauchi S, Onji M. Dendritic cells produce interleukin-12 in hyperthyroid mice. Eur J Endocrinol. (1999) 141:6259. doi: 10.1530/eje.0.1410625

107. Tamaru M, Matsuura B, Onji M. Increased levels of serum interleukin-12 in Graves' disease. Eur J Endocrinol. (1999) 141:111-6. doi: 10.1530/eje.0.1410111

108. Ganesh BB, Cheatem DM, Sheng JR, Vasu C, Prabhakar BS. GMCSF-induced CD11c+CD8a-dendritic cells facilitate Foxp3+ and IL-10+ regulatory $\mathrm{T}$ cell expansion resulting in suppression of autoimmune thyroiditis. Int Immunol. (2009) 21:269-82. doi: 10.1093/intimm/dxn147

109. Liu J, Cao X. Regulatory dendritic cells in autoimmunity: a comprehensive review. J Autoimmun. (2015) 63:1-12. doi: 10.1016/j.jaut.2015. 07.011

Conflict of Interest Statement: The authors declare that the research was conducted in the absence of any commercial or financial relationships that could be construed as a potential conflict of interest.

Copyright (C) 2019 Montesinos and Pellizas. This is an open-access article distributed under the terms of the Creative Commons Attribution License (CC BY). The use, distribution or reproduction in other forums is permitted, provided the original author(s) and the copyright owner(s) are credited and that the original publication in this journal is cited, in accordance with accepted academic practice. No use, distribution or reproduction is permitted which does not comply with these terms. 